\title{
A desumanização Presente nos Estereótipos de Î́ndios e Ciganos
}

\author{
Marcus Eugênio Oliveira Lima ${ }^{1}$ \\ André Faro \\ Mayara Rodrigues dos Santos \\ Universidade Federal de Sergipe
}

\begin{abstract}
RESUMO - Analisamos, em dois estudos realizados em Sergipe e Alagoas, a desumanização de duas minorias étnicas: índios e ciganos. Participaram 678 não indígenas de ambos os sexos. No primeiro estudo, foram 378 moradores de cinco cidades de Sergipe e uma de Alagoas, dos quais 104 viviam perto da única tribo indígena do estado de Sergipe. No segundo, participaram 300 não-ciganos, dos quais 153 viviam perto de comunidades ciganas. Realizaram-se entrevistas individuais sobre as representações sociais e crenças coletivas acerca de ciganos e índios. Verificamos que os índios são representados como exóticos e invisíveis, predominando crenças coletivas neutras ou de exclusão moral. Quanto aos ciganos, o processo de desumanização foi mais flagrante, predominando a exclusão moral e a deslegitimação.
\end{abstract}

Palavras-chave: Estereótipos, índios, ciganos, relações étnicas e raciais, atitudes étnicas e raciais.

\section{Dehumanization in the Stereotypes of Indigenous People and Gypsies}

\begin{abstract}
We analyzed, in two studies carried out in Sergipe and Alagoas, the dehumanization of Gypsies and Indians. A total of 678 male and female subjects participated. In the first study 378 non-Indians from five cities in Sergipe and Alagoas collaborated, 104 of them living close to the only indigenous tribe in Sergipe. The second involved 300 non-gypsies, 153 of them living close to Gypsy communities. The studies consisted of individual interviews inquiring about social representations and neutral collective beliefs about Gypsies and Indigenous People. We found that indigenous people were represented as exotics and invisible, and neutral collective beliefs or moral exclusion predominated. In relation to gypsies, the dehumanization process was more blatant, predominating moral exclusion and delegitimization.
\end{abstract}

Keywords: Stereotypes, indians, gypsies, racial and ethnic relations, racial and ethnic attitudes.

A inferiorização e desumanização da diferença é algo que acompanha a nossa história, marca os encontros intergrupais e opera integrando traços físicos e biológicos a teorias implícitas de personalidade, como fica claro na tese clássica do biologista Karl Linneaus (1707-1778), que classificou a espécie humana em quatro grupos: (a) Indios americanos - coléricos, rígidos, obstinados, possuem cabelos pretos e lisos, rosto severo, barba rala e pele cor de cobre. Estariam contentes apenas quando em liberdade e seriam regulados pelos constumes e tradições; (b) Europeus - gentis, inventivos e inteligentes. Teriam cabelos loiros ou marrons e olhos azuis. Seriam governados pelas leis; (c) Asiáticos melancólicos, severos, rígidos e avarentos. Teriam cabelos e olhos escuros e seriam governados por opiniões; (d) Africanos - relaxados, espertos, preguiçosos e negligentes. Teriam a pele, os olhos e os cabelos escuros e seriam regidos por caprichos (Popkin, 1999).

Essa forma de representação do outro foi a base retórica utilizada para justificar a escravidão e o extermínio durante muitos períodos da nossa história. Com efeito, a associação de traços físicos a traços morais e sociais juntamente com a hierarquização e essencialização das diferenças são os princípios operativos fundamentais de todas as formas de racismo (Lima \& Vala, 2004).

1 Endereço para correspondência: Avenida Marechal Rondon, sem número, Jardim Rosa Elze, Cidade Universitária Professor José Aloísio de Campos, São Cristóvão, Departamento de Psicologia (DPS), São Cristóvão,SE, Brasil. CEP 49.000-000.E-mail: meolima@uol.com.br
Mas será que ainda pensamos assim nos dias de hoje? E será que no Brasil, país marcado pela mistura racial, negros, índios e outras minorias étnicas são inferiorizados? Será que isso acontece na região mais miscigenada do país, o Nordeste ${ }^{2}$ ?

A construção de imagens do outro que justifiquem a violência ou a indiferença contra ele é, como refere Staub (1989), um primeiro e fundamental passo para o genocídio, o holocausto e a violência de massa. Neste artigo, analisamos o conteúdo e a estrutura dos estereótipos ou imagens de duas minorias sociais historicamente inferiorizadas no Brasil: índios e ciganos. Nosso objetivo é entender como tais imagens colaboram para o processo de desumanização desses grupos e em que medida a distância ou proximidade em relação aos membros dessas minorias sociais interfere nesse processo. A desumanização, neste trabalho, é entendida como um processo de percepção do outro, classificado como minoritário no contexto de uma relação assimétrica de poder, que colabora para a perpetração e legitimação de várias formas de violência ele, representando-o como não humano, demoníaco, objeto/coisa, representante do mal, que precisa ser preso, isolado, aniquilado.

2 Dados do Censo apontam que, em 2010, o maior contingente de cidadãos que se auto-classificam como pardos vive na região Nordeste. Dos 82 milhões de brasileiros pardos mais de 34 milhões eram nordestinos (IBGE, 2010). 


\section{O Papel da Distância e da Proximidade nos Estereótipos e na Desumanização}

A desumanização e outros processos de exclusão apoiam-se consideravelmente em dois processos cognitivos: a categorização social e o essencialismo. Segundo Tajfel (1982), a categorização social permite reunir objetos, pessoas ou acontecimentos sociais em grupos "que são equivalentes no que diz respeito às acções, intenções e sistemas de crenças do indivíduo" (pp. 288-289). O essencialismo, por sua vez, seria a tendência a agir e pensar como se todas as coisas possuíssem algo intrínseco que as tornam o que são (Medin, 1989).

Os processos sociais de classificação localizam indivíduos em grupos: endogrupos (grupos aos quais o indivíduo pertence) e exogrupos (grupos aos quais não pertence). A cada classificação que separa "nós" e "eles", agregam-se imagens que permitem representar os outros como diferentes de nós. Essas imagens são os estereótipos, que podem ser definidos como um conjunto de características que são associadas a uma categoria social (Stangor, 2000).

$\mathrm{Na}$ análise dos estereótipos e do preconceito, merece destaque a tese da dissociação entre crenças coletivas e pessoais. Devine (1989) propõe que as crenças coletivas sobre os grupos (estereótipos culturais), largamente difundidas nos processos de socialização, muitas vezes implicam preconceito, ainda que combatidas pelas crenças pessoais. Stangor (2000), na mesma direção, refere que os estereótipos podem ser individuais e culturais, positivos ou negativos.

Algumas formas negativas de estereotipia distanciam os grupos representados daquilo que tipifica os seres humanos (cultura), aproximando-os daquilo que tipifica os animais ou as coisas inanimadas (natureza). Quando essas representações da alteridade emergem, estamos diante do fenômeno da desumanização, que se define como a negação da completa humanidade aos outros (Haslam, 2006). A desumanização decorre da criação de hierarquias entre os grupos, em que um se considera mais humano que outro. Nesse caso, um dos grupos se afirma possuidor de características especiais e, simultaneamente, nega ao outro a posse de tais atributos.

Haslam e Loughnan (2014) propõem que a percepção de outro ser humano como menos dotado de humanidade é um fenômeno social antigo e persistente na nossa história:

As vitimas de genocídio eram chamadas de vermes pelos perpetradores. Os escravos eram vistos como não valendo uma fração de uma pessoa. Os imigrantes eram associados a pestes invasivas e a doenças infecciosas. Jogadores de futebol negros são saudados com imitações de macacos em estádios europeus. Índios são estereotipados como selvagens em oposição a nobres. $(\mathrm{p} .401)^{3}$

A desumanização opera por variados caminhos. Pode ocorrer através da negação ou diminuição da capacidade do outro de expressar sentimentos (Leyens et al., 2000), ou de possuir uma cultura (Moscovici \& Pérez, 1999), de adotar valores (Struch \& Schwartz, 1989), ou de ser moralmente considerável (Opotow, 1990), além da descrição em termos extremamente negativos e deslegitimadores (BarTal, 1989) ou ainda como um ser demonizado (Reguera,

\footnotetext{
3 Tradução nossa.
}

2008).Trata-se, portanto, de representar o outro como menos possuidor de traços exclusivamente humanos, aqueles que refletem socialização, moralidade, cultura, refinamento e aprendizagem (Haslam, 2006). Grosso modo, a desumanização pode acontecer de duas formas: na forma animalizante, quando as pessoas são associadas a animais; e na forma mecanicista, quando as pessoas são percebidas como objetos/máquinas (Haslam, 2006).

A desumanização desempenha funções psicológicas, sociais e políticas. No que se refere às funções psicológicas, permite aos perpetradores e espectadores proteção contra a violência cometida, evitando sentimentos de culpa, piedade e altruísmo (Leyens et al., 2003). No que se refere às funções sociais, possibilita que endogrupos em situações de competição material ou simbólica se sintam superiores a outros, promovendo e legitimando a exclusão social e moral (Viki, Osgood, \& Phillips, 2013). No que se refere às funções políticas, produz justificativas para a institucionalização das violências e massacres contra grupos com menos poder (Gwinn, Judd, \& Park, 2013). Não é sem razão que a maioria dos casos de genocídio utiliza a desumanização nas suas retóricas de legitimação. É nesse sentido que o processo de desumanização é um ingrediente essencial na realização da maldade (Castillo, Bello, Piñero, \& Leyens, 2008; Staub, 1989; Zimbardo, 2008).

Blumer (1958) propõe que a construção de imagens desumanizadoras é a condição fundamental do preconceito, juntamente com a percepção de ameaça à relação de dominação de um grupo sobre o outro. Para esse autor, o preconceito seria um tipo de sentimento que ocorre sob certas condições nas relações intergrupais. O sentimento de superioridade em relação ao outro o coloca em uma posição de inferioridade; o sentimento de diferenciação constrói uma distância simbólica em relação a ele; o sentimento de propriedade ou de posse exclui o outro das prerrogativas da posição; e, finalmente, o sentimento de medo decorre da percepção de ameaça à posição de dominação sobre o outro.

De acordo com a teoria do Senso de Posição Grupal, a construção de imagens e sentimentos intergrupais é marcada pela distância e pela proximidade simbólica e física entre os grupos envolvidos, uma vez que esses vetores (distância e proximidade) podem produzir ameaça à posição do grupo (Blumer, 1958). Na mesma direção, Simmel (1950) afirma que o "estrangeiro" é alguém que está ao mesmo tempo longe e perto de nós, visto que, mesmo quando fisicamente próximo, permanece a distância cultural. Na mesma direção, Jodelet (1998) propõe que a elaboração da diferença é produzida internamente pelos grupos como forma de proteção do endogrupo e externamente como desvalorização e inferiorização do exogrupo.

A análise do papel da proximidade e da distância nas relações intergrupais estrutura uma hipótese clássica na psicologia social, a hipótese do contato de Gordon Allport (1954). Esse autor propõe que a proximidade ou o contato, sob certas circunstâncias ideais, são um poderoso antídoto contra o preconceito. As circunstâncias ideais seriam: (a) interações ocorrendo em situações de status igual entre os dois grupos; (b) o desenvolvimento de atividades com objetivos comuns aos dois grupos; (c) o estabelecimento de relações personalizadas e próximas entre os membros dos 
dois grupos; e (d) o apoio das autoridades e instituições ao contato. Quando cumpridas essas condições, o contato entre os grupos pode reduzir o preconceito. Pettigrew e Tropp (2006), em uma ampla meta-análise, constataram que, de fato, o contato reduz o preconceito.

Entretanto, na vida real, as condições de contato ideal e efetivo propostas por Allport (1954) são quase sempre impossíveis de se realizarem. Quando isso ocorre, o contato ou a proximidade intergrupal pode aumentar, ao invés de diminuir, o preconceito. Triandis e Vassiliou (1967), em um estudo clássico com participantes gregos e norte-americanos, enfocam o papel da proximidade entre os grupos nos estereótipos. Eles consideram três condições de contato: alto contato (contato diário), médio contato e baixo contato. Os autores verificam que, na condição de alto contato, os participantes norte-americanos elevam o nível de competição em relação aos gregos e apresentam estereótipos mais negativos contra essa categoria social. Considerando essa perspectiva, neste trabalho analisamos o papel da distância e da proximidade (indicadores de contato) em relação a índios e ciganos, a fim de avaliar como operam estereótipos desumanizadores frente a esses grupos.

\section{A Desumanização nos Estereótipos dos Índios e Ciganos no Brasil}

A história brasileira de exploração e desumanização dos índios é ainda anterior ao surgimento do Brasil enquanto nação. Os índios foram a "minoria primeira", invadida pela diferença cultural e física de modo violento e assimilador (Wieviorka, 2002). Não obstante sua importância na constituição do ethos nacional, há pouco interesse da psicologia social e de outras áreas de conhecimento em pesquisar o preconceito contra essa categoria social.

Segundo levantamento realizado pelo IBGE em 2010, tínhamos no Brasil pouco mais de 800 mil indígenas (IBGE, 2012), uma população em crescimento demográfico, visto que, em 2001, eram 572 mil (IBGE, 2000). Em 2000, 44\% viviam em zonas urbanas e $42 \%$ deles estavam fora das terras indígenas. De acordo com esses dados, os índios se encontram numa condição de exclusão social e moral: 51\% não possuíam renda fixa e $32,5 \%$ possuíam renda inferior a R\$ 576,00 (IBGE, 2000). Em 2010, os índios possuíam o mais baixo valor médio do rendimento mensal nos grupos de cor do Brasil: $\mathrm{R} \$ 735,00$, contra $\mathrm{R} \$ 1538,00$ dos brancos e $\mathrm{R} \$$ 834,00 dos negros. Ou seja, o rendimento médio de um índio perfazia $47,8 \%$ do rendimento de um branco (IBGE, 2012).

A exclusão social e econômica dos índios é acompanhada pela exclusão cultural e simbólica. A imagem social dessa categoria social ao longo da nossa história transita do cruel e subumano canibal ao selvagem infantil e ingênuo (Ribeiro, 2005). Mesmo na atualidade, estudos mostram que muitos dos povos indígenas ainda são vistos como bárbaros ou primitivos, percebidos sem nenhum tipo de refinamento ou "civilidade", e suas características são associadas às de animais ou de crianças (Lima \& Almeida, 2010; Torres, Martignoni, \& Oliveira, 2011).

Estudos mostram que o contato com os índios, em situação de competição social, pode aumentar o preconceito contra essa categoria. Torres et al. (2007), observaram, estudando os estereótipos sobre os índios em Goiás, que o nível de contato com os índios em zonas urbanas aumenta o preconceito contra eles: quanto mais contato, mais preconceito. Venturi e Bokany (2013), em uma ampla pesquisa realizada em 2010, envolvendo 2006 entrevistas com cidadãos de todas as regiões do Brasil, observaram que $3 \%$ dos brasileiros quando perguntados sobre "grupos de pessoas que não gosta de encontrar" responderam grupos raciais e étnicos. Na pergunta sobre o grupo que menos gostam de encontrar, os índios foram citados $1 \%$ das vezes, ocupando a $9^{\circ}$ posição nessa escala de mal querência. Com a pergunta "Os índios são selvagens, querem resolver tudo a força" os autores observaram que, nas regiões Norte $(42 \%)$, Nordeste e Centro-Oeste (30\% em ambas), foram encontradas as maiores taxas de concordância e que esta crença é maior entre os que vivem longe (30\%) do que entre os que moram próximos a tribos indígenas $(24 \%)$. A crença no índio preguiçoso foi maior nas regiões Norte (34\%) e Sul $(29 \%)$, sendo que os que moram perto ou longe de tribos não se diferenciaram ( $21 \%$ de concordância para ambos). Houve ainda, nas Regiões Norte $(9 \%)$ e Sul $(6 \%)$, quem concordasse com a afirmação "Índio bom é índio morto". No Nordeste, $4 \%$ concordaram com esta frase, sendo $5 \%$ dos que viviam longe e $3 \%$ dos que viviam perto de tribos. Independentemente da região pesquisada e de viver longe ou perto dos índios, $80 \%$ da amostra concordou que existe preconceito contra os índios no Brasil. Ainda que poucos admitissem ter preconceito contra eles, o valor mais alto de preconceito pessoal foi encontrado no Nordeste (7\%), sendo que $4 \%$ dos que moravam próximo e $3 \%$ dos que viviam longe de tribos admitiram ter preconceito contra os índios.

A história das representações sociais dos ciganos é semelhante, em alguns aspectos, à história dos índios. Em um primeiro momento dos contatos intergrupais, até meados do século $\mathrm{XV}$, eles eram aceitos pelos não-ciganos e mesmo ajudados, recebendo teto temporário e esmolas (Moscovici \& Pérez, 1999). Todavia, no século XVI, quando migraram de Portugal para o Brasil, os ciganos já eram alvo de preconceito e discriminação, sendo associados à violência e ao crime e excluídos pela justificativa de pertencerem a uma "raça inferior e vadia" (Borges, 2007).

No Brasil de hoje estima-se a existência de mais de meio milhão de ciganos (IBGE, 2000). A desumanização desse grupo se manifesta abertamente, sendo pouco afetada pela norma antirracista. Apenas em 2002, o Governo começou a discutir políticas para ciganos através de programas em prol dos seus direitos ${ }^{4}$ (Souza, Bonomo, Livramento, Brasil, \& Canal, 2009).

Estudos demonstram que os estereótipos negativos dos ciganos geralmente os descrevem como vadios, delinquentes, desonestos e preguiçosos. Já as mulheres ciganas, por causa da prática da "buena-dicha" (leitura de mãos), são associadas a bruxas, embusteiras e mistificadoras (Teixeira, 2008). O mesmo autor verifica ainda que os ciganos são estereotipados como sujos, hereges, pagãos e ateus por não frequentarem a igreja e realizarem seus próprios rituais matrimoniais ou

4 http://www.seppir.gov.br/.arquivos/guia-de-politicas-publicas-para-povos-ciganos 
funerários. No estudo já citado de Venturi e Bokany (2013), na pergunta sobre o grupo que os brasileiros entrevistados menos gostavam de encontrar, os ciganos foram referidos em $12 \%$ das repostas, sendo superados apenas por "usuários de drogas" e "gente que não acredita em Deus". Apesar desses estereótipos negativos, os ciganos são vistos ainda como bons músicos e dançarinos em função das suas práticas culturais (Bonomo et al., 2010).

Tomando por base esses postulados, realizamos dois estudos para investigarmos o processo de desumanização dos índios e ciganos em Alagoas e Sergipe. No primeiro estudo, analisamos os estereótipos dos índios, considerando como ancoragem o nível de contato (pessoas que vivem perto e pessoas que vivem distante da única tribo indígena no estado de Sergipe). No estudo dois, foram os ciganos o grupo sobre o qual se pesquisou os estereótipos, considerando novamente os efeitos do contato (viver perto ou longe de comunidades ciganas). Todos os procedimentos éticos para realização de pesquisas com humanos foram devidamente seguidos ${ }^{5}$.

Considerando a estreita relação entre crenças estereotípicas e representações sociais (Fraser, 1994), adotouse, como suporte metodológico, a abordagem estrutural das representações sociais, perspectiva na qual a representação ou imagem social é entendida como um campo simbólico estruturado em elementos hierarquicamente organizados, sendo alguns mais centrais e outros mais periféricos (Abric, 1998). Acreditamos que os elementos da representação se estruturam como um conhecimento dialógico gerado num processo relacional que envolve três dimensões: Alter-EgoObjeto (Marková, 2006).

O Núcleo Central é povoado pelos elementos mais frequentes e referidos como mais importantes na representação. São os elementos pertencentes a esse núcleo que mantém a estabilidade das representações. A Zona de Contraste (ZC) é composta por elementos que mesmo não sendo muito frequentes, quando referidos são considerados como altamente importantes. A ZC é responsável pelas mudanças e dinamicidade nas representações. O sistema periférico comporta enunciações pouco referidas e com baixa ordem de importância, suportando assim a heterogeneidade dentro das representações e admitindo a flexibilidade das mesmas (Sá, 2002).

Nossa hipótese geral, tendo em conta a Teoria do Senso de Posição Grupal de Blumer (1958), é a de que os participantes que vivem próximos a comunidades ciganas e indígenas apresentarão mais elementos desumanizadores nos estereótipos desses grupos que os que vivem longe.

\section{Estudo 1}

Neste estudo, analisamos as crenças pessoais e coletivas e as imagens sobre os índios. Interessava entender se viver perto ou distante de uma tribo indígena, competindo ou não com ela por recursos materiais, tinha algum efeito na percepção desumanizadora desse grupo.

5 A pesquisa foi aprovada no Comitê de Ética de Pesquisa com seres Humanos da Universidade Federal de Sergipe, sob o protocolo $n^{\circ} \mathrm{CAAE}$ 0087.0.107.000-10.

\section{Método}

Participantes. Colaboraram 378 moradores de cinco cidades de Sergipe (Aracaju 129, Estância 58, Itabaiana 34, Lagarto 53 e Porto da Folha 50) e uma de Alagoas (Pão de Açúcar 54). As cidades foram escolhidas por serem as principais das microrregiões do Estado (Lagarto, Itabaiana e Estância), por ser a capital (Aracaju) ou por serem as mais próximas da tribo indígena de Sergipe (Porto da Folha e Pão de Açúcar). Os entrevistados foram, em sua maioria, mulheres (52.3\%), com idades entre 18 e 83 anos $(M=34.6$, $D P=15)$.

Procedimentos e materiais. Para investigar as imagens dos grupos utilizamos um roteiro de entrevista estruturada no qual constavam associações-livres. Os participantes deveriam informar quais as três primeiras palavras, sentimentos ou pensamentos que thes viessem à mente quando ouviam a palavra "índios". Em seguida, deveriam indicar a ordem de importância de cada enunciação. Para investigar os estereótipos, perguntamos quais seriam as características, os traços de personalidade ou os modos de ser considerados pela sociedade brasileira, de uma maneira geral, como mais típicos dos índios, bem como quais o próprio entrevistado consideraria como típicos. Utilizamos os softwares EVOC 2000 (5.0) e SPSS 18.0 para a análise dos dados.

\section{Resultados e Discussão}

Os resultados da análise das evocações indicam que as imagens construídas sobre os índios objetivam-se, sobretudo, na percepção de distância cultural e física. A evocação mais frequente foi a das "práticas culturais", com 298 enunciações, categoria formada por termos que fazem referência a um índio exótico, com hábitos e práticas distantes e diferentes. Esta também foi a evocação mais central. Há poucas diferenças entre as imagens construídas sobre os índios para os que vivem longe e perto. Apenas as objetivações dos índios como "exóticos" ou "pitorescos" foram ligeiramente mais comuns nos que vivem longe (Tabela 1).

No que se refere às crenças pessoais e coletivas sobre os índios, notamos uma configuração que mescla a face dos índios como sendo discriminados e excluídos com estereótipos ainda do tempo da colonização: a ideia do índio selvagem. Aparecem também elementos de deslegitimação e exclusão moral, expressos nos traços "preguiçosos", "aproveitadores", "inferiores" e "perigosos/violentos" (Tabela 2).

Para analisar as relações entre morar perto ou longe e a desumanização presente nos estereótipos, compusemos um indicador de desumanização considerando as seguintes dimensões e os respectivos traços ou caraterísticas atribuídos aos indígenas: Animalização (selvagens, inferiores, incapazes e sebosos); Deslegitimação (aproveitadores, preguiçosos, violentos, feios, perigosos, desorganizados e acomodados); e Exclusão Moral (invasores, arruaceiros, briguentos, arrogantes, gente que não presta, cachaceiros, desorganizados, acomodados, desconfiados, rígidos, destruidores, dominadores e descrentes). As demais caraterísticas atribuídas foram agrupadas nas categorias "Positivos" (pessoas boas, guerreiros, dispostos, 
trabalhadores, livres, importantes, inteligentes e unidos) e "Neutros" (necessitados, pobres, marginalizados, ignorados, ingênuos, injustiçados, menor população, etc.)

Os resultados indicam que $57,7 \%$ das crenças coletivas (estereótipos) dos que moram perto dos índios foram desumanizadoras, contra $65,0 \%$ de crenças desumanizadoras dos que vivem longe e, por suposto, mantêm menos contato. Predominam para os dois grupos pesquisados a dimensão da exclusão moral na desumanização dos índios. Esses resultados demonstram que a nossa hipótese de trabalho, que previa maior desumanização dos índios por parte daqueles que vivem perto não se confirma. Com efeito, as diferenças encontradas não são significativas $X^{2}(4)=3,65, \mathrm{p}=0,45$ (Tabela 3).
Esses resultados nos permitem concluir que o núcleo central das imagens sobre os índios é formado pela percepção das questões históricas e de que são importantes. Os que moram longe ainda acrescentam que são "primitivos", "isolados" e "naturais". A zona de contraste da representação é negativa e deslegitimadora para os que moram longe e positiva para os que moram perto. As objetivações desumanizadoras ("animalescos", "pessoas más", etc.) são mais frequentes entre os que moram longe que entre os que moram perto. Também as objetivações dos índios como "exóticos" ou "pitorescos" são mais comuns nos que vivem longe desse grupo.

Verificamos que quase todas as crenças coletivas sobre os índios referem a sua exclusão social e cultural, ao passo que

Tabela 1. Quadro de Quatro Casas das Representações sociais Associada aos Índios segundo Participantes que Moram Perto ou Longe Deles

\begin{tabular}{|c|c|c|c|c|c|c|}
\hline \multicolumn{7}{|c|}{ Núcleo central (Frequência $\geq 15$ e Classificação média < 2,0) } \\
\hline \multicolumn{3}{|c|}{$\underline{\text { Perto }}$} & \multicolumn{4}{|c|}{ Longe } \\
\hline Enunciações & Freq. ${ }^{1}$ & Ordem $^{2}$ & Enunciações & & Freq. & Ordem \\
\hline Questões históricas & 24 & 1,21 & Questões históricas & & 68 & 1,39 \\
\hline \multirow[t]{5}{*}{ Pessoas importantes } & 15 & 1,93 & Natureza & & 68 & 1,70 \\
\hline & & & Primitivos & & 26 & 1,65 \\
\hline & & & Isolados/desconhecidos & & 24 & 1,96 \\
\hline & & & Pessoas importantes & & 21 & 1,86 \\
\hline & & & Traços físicos & & 18 & 1,50 \\
\hline
\end{tabular}

$1^{\text {a }}$ Periferia (Frequência $\geq 15$ e Classificação média $\geq 2,0$ )

\begin{tabular}{|c|c|c|c|c|c|}
\hline \multicolumn{3}{|c|}{$\underline{\text { Perto }}$} & \multicolumn{3}{|l|}{ Longe } \\
\hline Enunciações & Freq. & Ordem & Enunciações & Freq. & Ordem \\
\hline Práticas culturais & 61 & 2,08 & Práticas culturais & 237 & 2,09 \\
\hline Traços morais positivos & 18 & 2,11 & Explorados escravizados & 41 & 2,02 \\
\hline \multirow[t]{3}{*}{ Explorados/escravizados } & 15 & 2,00 & Exclusão/pobreza & 28 & 2,04 \\
\hline & & & Modos de vida (livres, vivem ao ar livre, etc.) & 22 & 2,23 \\
\hline & & & Traços morais positivos & 22 & 2,27 \\
\hline
\end{tabular}

\begin{tabular}{|c|c|c|c|c|c|c|}
\hline \multicolumn{7}{|c|}{ Zona de contraste (Frequência < 15 e Classificação média < 2,0) } \\
\hline & & & & Longe & \multirow[b]{2}{*}{ Freq. } & \multirow[b]{2}{*}{ Ordem } \\
\hline Enunciações & Freq. & Ordem & Enunciações & & & \\
\hline Bonitos & 9 & 1,78 & \multirow[t]{7}{*}{ Pessoas más } & & \multirow[t]{7}{*}{13} & \multirow[t]{7}{*}{1,85} \\
\hline Seres humanos & 8 & 1,62 & & & & \\
\hline Xocós/família & 6 & 1,00 & & & & \\
\hline Guerreiros & 6 & 1,67 & & & & \\
\hline Diferentes & 5 & 1,60 & & & & \\
\hline Traços físicos & 5 & 1,80 & & & & \\
\hline Pessoas más & 4 & 1,25 & & & & \\
\hline \multicolumn{7}{|c|}{$2^{a}$ Periferia (Frequência $<15$ e Classificação média $\geq 2,0$ ) } \\
\hline \multicolumn{3}{|c|}{$\underline{\text { Perto }}$} & \multicolumn{4}{|c|}{ Longe } \\
\hline Enunciações & Freq. & Ordem & Enunciações & & Freq. & Ordem \\
\hline Civilizados & 6 & 2,00 & Animalescos & & 9 & 2,11 \\
\hline Isolados/desconhecidos & 5 & 2,60 & & & & \\
\hline Animalescos & 2 & 2,00 & & & & \\
\hline
\end{tabular}

Nota. ${ }^{1}$ Frequência absoluta; ${ }^{2}$ Ordem de Classificação 


\section{Estudo 2}

Tabela 2. Frequências Percentuais do Conteúdo das Crenças Coletivas Associadas aos Índios

\begin{tabular}{lcc}
\hline Imagens dos índios & Frequência & Percentagem \\
\hline Discriminados/Excluídos & 74 & 19,6 \\
Selvagens & 42 & 11,1 \\
Aproveitadores/preguiçosos & 40 & 10,6 \\
Diferentes & 26 & 6,9 \\
Inferiores/incapazes/ & 25 & 6,6 \\
ignorantes & & \\
Perigosos/violentos & 13 & 3,7 \\
Pessoas normais & 12 & 3,2 \\
Invasores & 11 & 2,9 \\
Pessoas boas & 10 & 2,6 \\
Não respondem & 12 & 3,2 \\
Outras respostas (frequência & 88 & 29,9 \\
inferior a 10) & & \\
\hline Total & 353 & $100 \%$ \\
\hline
\end{tabular}

Tabela 3. Frequências e Percentuais do Conteúdo Desumanizador dos Estereótipos (Crenças Coletivas) Associados aos Índios em Função do Nivel de Contato com Eles.

\begin{tabular}{|c|c|c|}
\hline \multirow{2}{*}{$\begin{array}{c}\text { Dimensões da } \\
\text { desumanização }\end{array}$} & \multicolumn{2}{|c|}{ Nível de contato } \\
\hline & $\frac{\text { Baixo contato }}{\text { Morar longe }}$ & $\frac{\text { Elevado contato }}{\text { Morar perto }}$ \\
\hline Animalização & $43(15,8 \%)$ & $12(11,5 \%)$ \\
\hline Deslegitimação & $26(9,5 \%)$ & $16(15,4 \%)$ \\
\hline Exclusão Moral & $81(29,7 \%)$ & $32(30,8 \%)$ \\
\hline Traços positivos & $53(19,4 \%)$ & $17(16,3 \%)$ \\
\hline Traços neutros & $70(25,6 \%)$ & $27(26,0 \%)$ \\
\hline Total & $273(100,0 \%)$ & $104(100,0 \%)$ \\
\hline
\end{tabular}

as crenças pessoais referem a sua fragilidade, normalidade e espiritualidade. Predominando crenças neutras de modo geral e, de um modo específico, as negativas sobre as positivas. Vimos ainda que a principal forma de desumanização dos índios foi a exclusão moral e que o nível de contato não tem o impacto hipotetizado na desumanização. Pensamos que isso pode se dever ao fato de que os que moram perto dos índios em Sergipe não mantêm com eles relações de competição material ou simbólica. Os índios da única tribo do Estado, os Xocós, vivem sozinhos numa Ilha, Ilha de São Pedro, e frequentam as zonas urbanas de Porto da Folha e Pão de Açúcar apenas para comprarem e venderem seus produtos, diferentemente dos índios pesquisados no estudo de Torres et al. (2007), em Góias. Nossos resultados vão na mesma direção dos encontrados por Venturi e Bokany (2013). Naquele estudo, vimos que também não havia grande diferença no preconceito contra os índios para os que viviam perto e os que viam longe de tribos; sendo a crença de que "índio bom é índio morto" um pouco mais forte entre os que vivem longe e o preconceito pessoal um pouco maior dentre os que viam perto.
Neste estudo, indagamos sobre como se opera desumanização para uma minoria marcada pela resistência e diferenciação cultural: os ciganos. Consideramos, assim como no estudo 1, o fato de viver perto ou distante de comunidades ciganas um estruturador das imagens e dos processos de desumanização a elas associados.

\section{Método}

Participantes. Colaboraram 300 não-ciganos. Destes, 153 vivem perto de comunidades ciganas situadas em três localidades: Japoatã (60 entrevistados), Umbaúba (56) e São Cristóvão (37); sendo $61,2 \%$ do sexo feminino, com idades variando de 18 a 83 anos $(M=34,4 ; D P=15,2)$. Dentre os 147 entrevistados que moravam distante de comunidades ciganas, $61,9 \%$ são do sexo feminino, com idades entre 18 e $61 \operatorname{anos}(M=28,5 ; D P=11,0)$.

Procedimentos e materiais. À semelhança do estudo anterior, utilizamos um roteiro de entrevista estruturada. As análises de dados e as perguntas realizadas foram iguais às do primeiro estudo, com uma única diferença: para investigar as crenças coletivas, utilizamos, neste estudo, a seguinte questão: “O que você já ouviu falar sobre ciganos?”.

\section{Resultados e Discussão}

Os dados apresentados na Tabela 4 indicam que a associação livre com a palavra "ciganos" mostrou que o núcleo central da representação formada pelos que vivem perto é fortemente desumanizador ("diferentes", "criminosos", "medo"); enquanto que, para os que vivem longe, predomina a visão do exotismo dos ciganos ("nômades", "aparência", "exotismo"), com alguma exclusão moral ("trambiqueiros" e "vagabundos"). Por outro lado, na zona de contraste, observamos que os que vivem perto se aproximam dos ciganos, com a resposta "iguais a nós"; mas, simultaneamente, os desumanizam, representandoos como "desumanos". Os que moram distantes, por sua vez, representam-nos de modo deslegitimador ("medo", "crimes", "diferentes"). A imagem dos ciganos encontrada é flagrantemente desumanizadora, integrando na sua composição as visões históricas do misticismo cigano, à exclusão moral e à deslegitimação do grupo, como já haviam observado outros autores (Filho, 1981; Moscovici \& Pérez, 1999; Teixeira, 2008).

As crenças coletivas ou estereótipos sobre os ciganos são também abertamente negativos. A imagem de que eles estão ligados ao roubo é a mais frequente, seguida da visão de que "levam uma vida fácil", são "enganadores, trapaceiros". O estereótipo do cigano como violento também é marcante, totalizando $14,1 \%$ das respostas ("briguentos", "violentos", "matam"). Enfim, mais de 58,0\% das respostas referem estereótipos negativos dos ciganos, isso considerando apenas as respostas com frequência não inferior a dez (Tabela 4).

A fim de testarmos nossa hipótese, construímos, à semelhança do primeiro estudo, um indicador de desumanização. As dimensões de desumanização consideradas 
e os respectivos atributos foram: Animalização ("traiçoeiros", "agem impulsivamente", "tribo"), Deslegitimação ("matam", "se matam", "violentos", "perigosos", "não valem nada", "gostam de jogar praga", "pessoas ruins", etc.) e Exclusão Moral ("roubo", "ladrões", "assaltantes", "enganadores", "trapaceiros", "fazem coisas erradas", "briguentos", "traficantes", "perigosos", "não são confiáveis", "invasores", "desconfiados", "mal educados", "não trabalham”, etc.). Compusemos ainda uma dimensão dos traços neutros ("tem diferenças", "vendem trocam", "agiotas", "traços culturais", "pessoas excluídas", "crenças diferentes", etc.) e uma dimensão dos traços positivos ("boas pessoas", "unidos", "persistentes", “destemidos", "bonitos", etc.).

Observamos que existe, neste caso, um efeito significativo do contato com os ciganos, $X^{2}(4)=14,82, p=0,005$. Na Tabela 6 , podemos ver que $62 \%$ das respostas dos que mantêm pouco contato desumanizam os ciganos contra $82 \%$ dos que vivem perto de comunidades ciganas. Observa-se ainda que a principal forma de desumanização dos ciganos é a exclusão moral, mais da metade das imagens formadas sobre esse grupo se objetivam nessa dimensão, com destaque para os que mantêm mais contato, que respondem dessa forma em $60 \%$ dos casos. Em todas as dimensões da desumanização, os que mantêm mais contato obtêm escores mais elevados. Os que moram longe dos ciganos e mantêm menos contato utilizaram mais traços estereótipos neutros que os que moram perto.

Os resultados encontrados nesse estudo indicam que morar perto ou longe das comunidades ciganas tem impacto no conteúdo e na estrutura das imagens sociais. Para os que moram perto, o núcleo central da representação é negativo e desumanizador; para os que moram longe predomina a visão do cigano místico e nômade. Interessa pontuar que a zona de contraste indica que morar perto implica em incluir para excluir os ciganos ("iguais a nós"); ao passo que para os que moram longe a alteridade forjada é a da exlusão radical: "diferentes" e "criminosos".

Retomando as teses de Blumer (1958), podemos afirmar que viver perto dos ciganos produz ameaça e medo e desencadeia nas pessoas um senso de posição grupal; viver

Tabela 4. Quadro de Quatro Casas das Representações Sociais Associadas aos Ciganos segundo Participantes que Moram Perto ou que Moram Longe Deles

\begin{tabular}{|c|c|c|c|c|c|c|}
\hline \multicolumn{7}{|c|}{ Núcleo central (Frequência $\geq 20$ e Classificação média < 2,0) } \\
\hline \multicolumn{3}{|c|}{$\underline{\text { Perto }}$} & \multicolumn{4}{|c|}{ Longe } \\
\hline Enunciações & Freq. ${ }^{1}$ & Ordem $^{2}$ & Enunciações & & Freq. & Ordem \\
\hline Diferentes & 61 & 1,74 & Nômade & & 61 & 1,69 \\
\hline Criminosos & 40 & 1,73 & Aparência & & 41 & 1,71 \\
\hline Briguentos & 40 & 1,87 & Misticismo & & 48 & 1,96 \\
\hline \multirow[t]{2}{*}{ Medo } & 31 & 1,81 & Trambiqueiros & & 28 & 1,96 \\
\hline & & & Vagabundos & & 25 & 1,88 \\
\hline
\end{tabular}

$1^{a}$ Periferia (Frequência $\geq 20$ e Classificação média $\geq 2,0$ )

$\underline{\text { Perto }}$

Longe

\begin{tabular}{|c|c|c|c|c|}
\hline Enunciações & Freq. Ordem & Enunciações & Freq. & Ordem \\
\hline & & Cultura & 45 & 2,22 \\
\hline & & Pobreza & 23 & 2,13 \\
\hline
\end{tabular}

Zona de contraste (Frequência $<20$ e Classificação média $<\mathbf{2 , 0}$ )

Perto

Longe

\begin{tabular}{lcclcc} 
Enunciações & Freq. & Ordem & Enunciações & Freq. & Ordem \\
\hline Nômade & 19 & 1,32 & Crimes & 1,59 \\
Iguais a nós & 19 & 1,37 & Diferentes & 1,88 \\
Desumanos & 16 & 1,81 & Dinheiro & 14 \\
Pobreza & 9 & 1,33 & Medo & 12 \\
Misticismo & 8 & 1,88 & Raça diferente & 1,91 \\
Pessoas unidas & 7 & 1,71 & História & 9 \\
\hline
\end{tabular}

$2^{\text {a }}$ Periferia (Frequência $<20$ e Classificação média $\geq 2,0$ )

\begin{tabular}{|c|c|c|c|c|c|}
\hline \multicolumn{3}{|c|}{$\underline{\text { Perto }}$} & \multicolumn{3}{|c|}{ Longe } \\
\hline Enunciações & Freq. & Ordem & Enunciações & Freq. & Ordem \\
\hline Aparência & 13 & 2,00 & Desumanos & 9 & 2,11 \\
\hline Dinheiro & 9 & 2,00 & Briguentos & 6 & 2,17 \\
\hline Cultura & 5 & 2,40 & Pessoas unidas & 7 & 2,57 \\
\hline
\end{tabular}

Nota. ${ }^{1}$ Frequência absoluta; ${ }^{2}$ Ordem de Classificação 
Tabela 5. Frequências Percentuais do Conteúdo das Crenças Coletivas Associadas aos Ciganos

\begin{tabular}{lcc}
\hline Imagens dos índios & Frequência & Percentagem \\
\hline Roubo/Ladrão/Assaltante & 115 & 22,5 \\
Enganadores/Trapaceiros/ & 58 & 11,3 \\
Levam vida fácil & & \\
Traços culturais & 42 & 8,2 \\
Vendem/ Trocam & 27 & 5,3 \\
Briguentos & 26 & 5,1 \\
Bravos/Violentos & 25 & 4,9 \\
Agiota/Empréstimo a juros & 21 & 4,1 \\
Matam/Matam entre eles & 21 & 4,1 \\
Bem de vida/ Riqueza & 14 & 2,7 \\
Não são confiáveis & 13 & 2,5 \\
Crenças: podem ver o futuro/ & 12 & 2,3 \\
feiticeiros & & \\
Coisas ruins & 11 & 2,1 \\
Não valem nada/não prestam & 10 & 2,0 \\
Outras respostas (frequência & 117 & 22,8 \\
inferior a 10) & & \\
\hline Total & 512 & 100 \\
\hline
\end{tabular}

Tabela 6. Frequências e Percentuais do Conteúdo

Desumanizador dos Estereótipos (Crenças Coletivas) Associados aos Ciganos em Função do Nivel de Contato com Eles.

\begin{tabular}{|c|c|c|}
\hline \multirow{2}{*}{$\begin{array}{c}\text { Dimensões da } \\
\text { desumanização }\end{array}$} & \multicolumn{2}{|c|}{ Nível de contato } \\
\hline & $\frac{\text { Baixo contato }}{\text { Morar longe }}$ & $\frac{\text { Elevado contato }}{\text { Morar perto }}$ \\
\hline Animalização & $1(0,7 \%)$ & $3(2,0 \%)$ \\
\hline Deslegitimação & $20(14,7 \%)$ & $29(19,6 \%)$ \\
\hline Exclusão Moral & $64(47,1 \%)$ & $90(60,8 \%)$ \\
\hline Traços positivos & $8(5,9 \%)$ & $5(3,4 \%)$ \\
\hline Traços neutros & $43(31,6 \%)$ & $21(14,2 \%)$ \\
\hline Total & $136(100,0 \%)$ & $148(100,0 \%)$ \\
\hline
\end{tabular}

longe faz acessar, sobretudo, uma representação do exotismo do grupo, remoteness nos termos de Simmel (1950). Esse resultado é confirmado quando analisamos os elementos de desumanização presentes nos estereótipos dos ciganos.

Confirma-se, portanto, a nossa hipótese de que os que mantêm mais contato produziriam maior desumanização. Chama ainda atenção o fato de que a exclusão moral predomina, sendo a forma de representar os ciganos para quase metade dos que mantêm pouco contato com eles e para quase $2 / 3$ dos que mantêm contatos frequentes.

\section{Discussão Geral}

O objetivo dos dois estudos que apresentamos neste trabalho foi analisar a desumanização dos índios e ciganos presente nas representações e estereótipos formados sobre essas minorias étnicas. Consideramos nos dois estudos que a percepção de ameaça, por um lado, e o contato por outro seriam os princípios organizadores das representações formadas.

No caso dos índios, as representações formadas são marcadas pela percepção da diferença cultural e pelo sentimento de indiferença em relação a essa minoria. Nas representações dos participantes, eles existem como uma ausência. Emblemática desse fenômeno de invisibilização é a predominância das crenças neutras em relação a essa minoria social. Podemos até afirmar que os indios são, para o grupo pesquisado em Sergipe, o equivalente aos habitantes da estrela Sirius para Simmel (1950).

Importa referir que outros estudos realizados em contextos urbanos, onde há mais competição entre índios e não índios por serviços sociais e recursos materiais, demonstram que a desumanização dos índios se apresenta como um repertório frequente nos estereótipos contra essa categoria social (Torres et al., 2011). No entanto, o estudo de Venturi e Bokany (2013), feito com amostra representativa da população brasileira e que também considerou viver próximo ou distante de tribos indígenas como princípio organizador das percepções sobre os índios, identificou, à semelhança da que encontramos no nosso estudo, uma visão neutra, pouco informada e com predominância do estereótipo do índio exótico, remoto. De forma mais específica, nosso estudo encontra que viver próximo a tribos reduz a visão do "índio exótico", ainda que não interfira no processo de desumanização do grupo. Dessa forma, o contato intergrupal, como proposto por Allport (1954), atua para combater certa ignorância ou desconhecimento sobre o grupo, mas não para controlar a estereotipia negativa. Como vimos, mais da metade das crenças coletivas expressas são desumanziadoras, com predomínio da exclusão moral e da animalização.

As imagens formadas sobre os ciganos são mais abertamente deslegitimadoras, e, sobretudo, de exclusão moral. As objetivações mais frequentes e importantes nas imagens desse grupo foram o medo, o crime e a percepção da diferença para os que vivem perto. Já para os de longe, o núcleo central traz o cigano nômade e pitoresco, mas também negativo. Resultados semelhantes são encontrados sobre os ciganos na Europa (Correia, Brito, Vala, \& Perez, 2001; Moscovici \& Pérez, 1999). O estudo de Venturi e Bokany (2013) demonstra ser esta uma categoria social vista muito negativamente no Brasil. Percebemos que viver perto dos ciganos, contrariamente à hipótese de Allport (1954) e na direção prevista por Blumer (1958) e por Triandis e Vassiliou (1967), aumenta o preconceito contra eles.

A principal forma de desumanização dirigida às duas minorias sociais pesquisadas foi a exclusão moral. Como refere Opotow (1990), a exclusão moral ocorre quando indivíduos ou grupos são percebidos como estando fora das fronteiras dentro das quais se aplicam as regras, os valores morais e as noções de justiça e igualdade. Dessa forma, excluir moralmente o outro significa não considerá-lo como merecedor de sentimentos positivos ou de ações de cuidado e apoio, em um diapasão no qual qualquer violência perpretada contra eles passa a ser legitima, como efetivamente tem ocorrido em relação aos índios e ciganos no Brasil.

Podemos concluir que existe uma relação entre o tipo de minoria, a norma social prevalente, o contato e os 
interesses estabelecidos nas relações e o tipo de racismo e desumanização perpetrada. Todavia, algumas limitações dos nossos estudos precisam ser destacadas. A noção de ameça ou de competição entre grupos que adotamos é um pouco simplificadora, pois restringimos à proximidade física entre os grupos as fontes de ameaça. Durante a coleta de dados, in loco, percebemos que morar perto não significa se sentir próximo ou ameaçado, pois, paralelamente aos processos de distintividade social (Tajfel, 1982), ocorrem processos de distinção simbólica. Desse modo, parece importante considerar, além da ameaça real, a ameaça simbólica, à semelhança de Stephan, Diaz-Loving e Duran (2000), como mediadora da desumanização em pesquisas futuras. Por outro lado, como referido, o contato intergrupal, para ser efetivo, tem que ocorrer em um campo relacional igualitário e com apoio institucional à inclusão social. Esse cenário está muito longe de ser real na atual relação entre os brasileiros não índios e não ciganos com essas duas minorias sociais. Para buscar combater a ignorância sobre esses grupos e estimular formas de contato intergrupal efetivo, consideramos importante as contribuições de novas investigações sobre as relações entre estereótipos, crenças pessoais e representações sociais de minorias étnicas.

\section{Referências}

Abric, J-C. (1998). A abordagem estrutural das representações sociais. In A. S. P. Moreira \& D. C. Oliveira (Eds.), Estudos Interdisciplinares de Representação Social (pp. 27-38). Goiânia: AB Editora.

Aguero, O. A. (2002). Sociedades indígenas, racismo y discriminación. Horizontes Antropológicos, 8(18), 255-264.

Allport, G.W. (1954/1979). The nature of prejudice (3rd. ed.). Wokingham: Addison-Wesley.

Bar-Tal, D. (1989). Group beliefs: A conception for analyzing group structure, processes, and behavior. New York: Springer-Verlag.

Blumer, H. (1958). Race prejudice as a sense of group position. The Pacific Sociological Review, 1(1), 3-7.

Bonomo, M., Souza, L. de, Brasil, J. A., Livramento, A. M., \& Canal, F. D. (2010). Gadjés em tendas Calons: Um estudo exploratório com grupos ciganos semi-nômades em território capixaba. Pesquisas e Práticas Psicossociais, 4(2), 160-171.

Borges, I. C. M. M. (2007). Cidades de portas fechadas: A intolerância contra os ciganos na organização urbana na Primeira República (Unpublished master's thesis). Universidade Federal de Juiz de Fora, Juiz de Fora (MG).

Castillo, M. N. Q., Bello, M. D. M., Piñero, A. D. C., \& Leyens, J-P. (2008). La maldad. In J., F., Morales-Dominguez, C. Huixi Casal, \& A. Gomez-Jimenez (Eds.), Método, teoría e investigación en Psicología Social (pp. 559-572). Madrid: Pearson-Educacion.

Correia, I., Brito, R., Vala, J., \& Perez, J. (2001). Normes antiracistes et persistance du racisme flagrant: Analyse comparative des attitudes face aux Tziganes et face aux noirs au Portugal. Buletinul Laboratorului Psihologia Câmpului Social, 15, 7-22.

Devine, P. G. (1989). Stereotypes and prejudice: Their automatic and controlled components. Journal of Personality and Social Psychology, 56, 1-18.
Dijker, A. J. (1987). Emotional reactions to ethnic minorities. European Journal of Social Psychology, 17, 305-325.

Filho, M. M. (1981). Os ciganos no Brasil e cancioneiro dos ciganos. São Paulo: Itatiaia.

França, D. X., \& Lima, M. E. O. (2011). Affirmative action policies and ethnic identity in black and indigenous children of Brazil. International Journal of Conflict and Violence, 5, 200-210.

Fraser, C. (1994). Attitudes, social representations and widespread beliefs. Papers on Social Representations, 3, 1-13.

Guimarães, A. S. A. (1999). Racismo e anti-racismo no Brasil. São Paulo: Editora 34.

Gwinn, J., Judd, C., \& Park, B. (2013). Less power = less human? Effects of power differentials on dehumanization. Journal of Experimental Social Psychology, 49, 464-70

Haslam, N. (2006). Dehumanization: An integrative review. Personality and Social Psychology Review, 10(3), 252-264.

Haslam, N., \& Loughnan, S. (2014). Dehumanization and infrahumanization. Annual Review of Psychology, 65, 399-423.

IBGE - Instituto Brasileiro de Geografia e Estatística. (2000). Pesquisa Nacional por Amostra de Domicílios - PNAD. Recuperado em 16 de setembro, 2014 de: <http://www.ibge. gov.br/home/estatistica/populacao/default censo 2000.shtm>

IBGE - Instituto Brasileiro de Geografia e Estatística. (2012). Censo demográfico brasileiro 2010. Rio de Janeiro, IBGE.

Jahoda, G. (1999). Images of savages: Ancient roots of modern prejudice in western culture. London: Routledge.

Jodelet, D. (1998). A alteridade como produto e processo psicossocial. In A. Arruda (Ed.), Representando a alteridade (pp. 47-67). Petrópolis: Vozes.

Jost, J.T., \& Thompson, E.P. (2000). Group-based dominance and opposition to equality as independent predictors of self-esteem, ethnocentrism, and social policy attitudes among African Americans and European Americans. Journal of Experimental Social Psychology 36, 209-232.

Lévi-Strauss, C. (2006). Raça e história (8th ed). Lisboa: Editorial Presença.

Leyens, J. P., Paladino, P., Rodriguez-Torres, R., Vaes, J., Demoulin, S., Rodriguez-Perez, A., \& Gaunt, R. (2000). The emotional side of prejudice: The attribution of secondary emotions to ingroups and outgroups. Personality and Social Psychology Review, 2, 186-197.

Leyens, J. P., Cortes, B., Demoulin, S., Dovidio, J. F., Fiske, S. T., Gaunt, R., ... Vaes, J. (2003). Emotional prejudice, essentialism, and nationalism: The 2002 Tajfel lecture. European Journal of Social Psychology, 33, 703-717.

Lima, M.E. O. (2007). Racial relations and racism in Brazil. Culture \& Psychology, 13, 461-473.

Lima, M. E. O., \& Almeida, A. M. M. de. (2010). Representações sociais dos índios em Sergipe: Ausência e invisibilização. Paidéia, 20(45), 17-27.

Lima, M. E. O., \& Vala, J. (2004). As novas formas de expressão do preconceito e do racismo. Estudos de Psicologia, 9, 401-411.

Marková, I. (2006). Dialogicidade e representações sociais: As dinâmicas da mente. Petrópolis: Vozes.

Medin, D. L (1989). Concepts and conceptual structure. American Psychologist, 44, 1469-1481.

Moscovici, S., \& Pérez, J. A. (1999). A extraordinária resistência das minorias à pressão das maiorias: $\mathrm{O}$ caso dos ciganos em Espanha. In J. Vala (Ed.), Novos racismos: Perspectivas Comparativas. Oeiras: Celta Editora. 
Opotow, S. (1990). Moral exclusion and injustice: An introduction. Journal of Social Issues, 46, 1-20.

Pereira, C. R., Torres, A. R. R., \& Almeida, S. T. (2003). Um estudo do preconceito na perspectiva das representações sociais: Análise da influência de um discurso justificador da discriminação no preconceito racial. Psicologia Reflexão $e$ Crítica, 16, 95-107.

Pettigrew, T. F., \& Meertens, R.W. (1995). Subtle and blatant prejudice in Western Europe. European Journal of Social Psychology, 25, 57-75.

Pettigrew, T.F., \& Tropp, L.R. (2006). A meta-analytic test of intergroup contact theory. Journal of Personality and Social Psychology, 90(5), 751-783.

Popkin, R. H. (1999). Eighteenth-century racism. In R. H. Popkin (Ed.), The Columbia History of Western Philosophy (pp. 508515). New York: Columbia University Press.

Reguera, G. B. (2008). De la demonización al racismo (sobre la deshumanización del otro). Criterio Jurídico. 8(2), 9-24

Rex, J. (1986/1988). Raça e etnia. Lisboa: Editorial Estampa.

Ribeiro, D. (2005). Os indios e a civilização: A integração das populações indígenas no Brasil. São Paulo: Companhia das Letras.

Sá, C. P. (2002). Núcleo central das representações sociais. Petrópolis-RJ: Vozes.

Santos, W. S. dos, Gouveia, V. V., \& Navas, M. S. (2006). Escala de racismo moderno: Adaptação ao contexto brasileiro. Psicologia em Estudo, 11, 637-645.

Schwarcz, L. M. (1996). As teorias raciais, uma construção histórica de finais do século XX: O contexto brasileiro. In L.M. Schwarcz \& R. da S. Queiroz (Eds.), Raça e Diversidade (pp. 147-185). São Paulo: EDUSP.

Sidanius, J. (1993). The psychology of group conflict and the dynamics of oppression: A social dominance perspective. In S. Iyengar \& W. McGuire (Eds.), Explorations in political psychology (pp. 183-219). Durham, NC: Duke University Press.

Simmel, G. (1950). The sociology of Georg Simmel. New York: Free Press.
Souza, L., Bonomo, M., Livramento, A. M., Brasil, J. A., \& Canal, F. D. (2009). Processos identitários entre ciganos: Da exclusão a uma cultura de liberdade. Liberabit, 15, 29-37.

Stangor, C., \& Shaller, M. (2000). Stereotypes as individual and collective representations. In C. Stangor (Ed.), Stereotypes and prejudice (pp. 64-82). Londres: Psychology Press.

Staub, E. (1989). The roots of evil: The origins of genocide and other group violence. Cambridge: Cambridge University Press.

Stephan, W. G., Diaz-Loving, R., \& Duran, A. (2000) Integrated threat theory and intercultural attitudes: Mexico and the United States. Journal of Cross-Cultural Psychology, 31, 240-249.

Struch, N., \& Schwartz, S. H. (1989). Intergroup agression: Predictors and distinctiveness from ingroup bias. Journal of Personality and Social Psychology, 56, 364-373.

Tajfel, H. (1982). Grupos humanos e categorias sociais. Lisboa: Livros Horizonte.

Torres, A. R. R., Martignoni, T. V. L., \& Oliveira, T. M. (2011). Contato, sentimentos intergrupais, identidade social, preconceito e dívidas históricas: $\mathrm{O}$ caso dos indígenas em Goiás. In E. M. Techio \& M. E. O. Lima (Eds.), Cultura e produção das diferenças: Estereótipos e preconceito no Brasil, Espanha e Portugal, (pp. 275-310). Brasília: Technopolitik.

Teixeira, R. C. (2008). História dos ciganos no Brasil. Recife: Núcleo de Estudos Ciganos.

Triandis, H. C., \& Vassiliou, V. (1967). Frequency of contact and stereotyping. Journal of Personality and Social Psychology, 7, 316-328.

Turra, C., \& Venturi, G. (1995). Racismo Cordial: A mais completa análise sobre preconceito de cor no Brasil. São Paulo: Ática.

Venturi, G., \& Bokany, V. (2013). Indígenas no Brasil - Demandas dos povos e percepções da opinião pública. São Paulo: Editora Fundação Perseu Abramo e Instituto Rosa Luxemburgo.

Viki, G., Osgood. D., \& Phillips S. (2013). Dehumanization and self-reported proclivity to torture prisoners of war. Journal of Experimental Social Psychology, 49, 325-28.

Wieviorka, M. (2002). A diferença. Lisboa: Fenda.

Zimbardo, P. (2008). The Lucifer Effect: Understanding how good people turn evil. Nova York: Random House. 